David Shulman B SC MD CCFP, H.B. Aronson mB FFakCs(1)

\title{
Capnography in the early diagnosis of carbon dioxide embolism during laparoscopy
}

\begin{abstract}
Venous embolism of carbon dioxide occurred during elective diagnostic laparoscopy in a healthy adult female. The diagnosis of gas embolism was made on the basis of the sudden abrupt onset of systolic and diastolic mutmurs. The continuousty recorded end-tidal carbon dioxide concentration $\left(\mathrm{FETCO}_{2}\right)$ increased abruptly from 3.8 to 4.2 per cent and then slowly decreased to 4.0 per cent over the subsequent 30 seconds. $\mathrm{CO}_{2}$ insuffation was terminated immediately following the establishment of the diagnosis. The patient recovered uneventfully. A transient but rapid rise in $\mathrm{FETCO}_{2}$ is suggested as a useful early sign of venous $\mathrm{CO}_{2}$ embolism during laparoscopy.
\end{abstract}

\section{Key words}

COMPLICATIONS; gas embolism, carbon dioxide embolism; MONITORING; end-tidal carbon dioxide.

Laparoscopy for gynaecologic diagnosis and therapy is a well established technique which, in skilled hands, has an acceptably low morbidity. A serious anaesthesia-related complication is embolization of the insufflating gas which was reported in 15 out of 113,253 gynaecologic laparoscopies under general anaesthesia ${ }^{1}$ and in one out of 63,845 laparoscopies for liver biopsy. ${ }^{2}$ This low incidence and the relative safety of the procedure ${ }^{1,3}$ may have led to complacency and a reluctance to routinely use invasive monitoring systems, such as the central

From the Department of Anaesthesia, Hadassah University Hospital, Mount Scopus, Jerusalem, Israel.

Address correspondence to: Dr. D. Shulman, Dept. of Anaesthesia, Hadassah University Hospital, Mount Scopus, P.O. Box 24035, Jerusalem, Israel 91240. venous line, which have been shown to be effective in detecting and treating air embolism during neurosurgery. ${ }^{4}$ However deaths have been reported from embolization of the insufflating gas, ${ }^{5-7}$ and therefore an examination of non-invasive monitoring is warranted in order to better predict and perhaps to prevent further mishaps. We have been monitoring laparoscopy patients with a precordial stethoscope and capnography and report our findings from an episode thought to be embolism of $\mathrm{CO}_{2}$.

\section{Case report}

A 32-year-old woman, ASA physical status class I, weighing $50 \mathrm{~kg}$, with primary sterility, was admitted for elective diagnostic laparoscopy. Heart sounds were normal preoperatively.

After premedication with meperidine $50 \mathrm{mg}$ and scopolamine $0.3 \mathrm{mg} \mathrm{IM}$, the indirect blood pressure was $105 / 65$ and heart rate 95 beats/min. Anaesthesia was induced with intravenous flunitrazepam $0.4 \mathrm{mg}$ and thiopentone $175 \mathrm{mg}$, and tracheal intubation carried out following gallamine $10 \mathrm{mg}$ and succinylcholine $90 \mathrm{mg}$. Ventilation was controlled, with a tidal volume of $600 \mathrm{ml}$, rate 10 breaths per minute, and with a total gas flow of 7 litres/min (nitrous oxide $51 /$ min and oxygen $21 / \mathrm{min}$ ). A Bain circuit was used. Fentanyl $0.15 \mathrm{mg}$ and a succinylcholine 0.1 per cent drip maintained anaesthesia. A precordial stethoscope was placed over the left fourth interspace and a Datex CD300 capnograph was connected via a side arm at the tracheal tube connector. (The capnograph was calibrated from two known $\mathrm{CO}_{2}$ sources and adjusted for the presence of $\mathrm{N}_{2} \mathrm{O}$ by an electrical offset switch. ${ }^{8}$ ) The initial fractional end tidal $\mathrm{CO}_{2}$ concentration $\left(\mathrm{FETCO}_{2}\right)$ was 3.8 per cent, equivalent to a partial pressure of $\mathrm{CO}_{2}$ in end tidal gas $\left(\mathrm{PETCO}_{2}\right)$ of $3.3 \mathrm{kPa}(25 \mathrm{mmHg}$ ). 


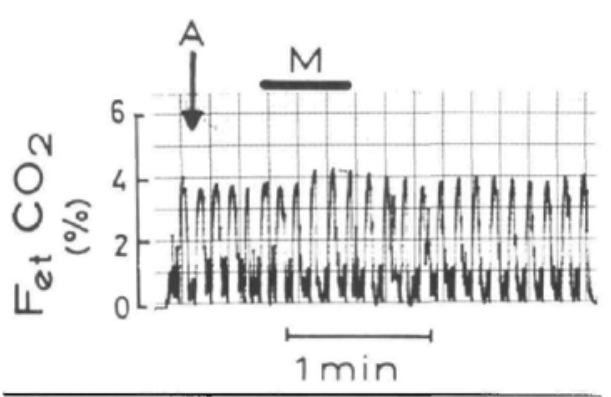

FIGURE I Fractional end tidal $\mathrm{CO}_{2}$ (per cent) vs time. Insuflation of $\mathrm{CO}_{2}$ started at A. Murmur heard and insufflation discontinued at $\mathrm{M}$.

The patient was placed in the horizontal lithotony position and a Verres needle introduced into the abdominal cavity at the umbilicus. Carbon dioxide was insufflated at $3 \mathrm{l} / \mathrm{min}$ from a Wisap $\mathrm{CO}_{2}$-pneu with $2.7-4.0 \mathrm{kPa}$ pressure recorded. Within approximately $20 \mathrm{sec}$ of the start of the insufflation, a loud coarse systolic murmur with a softer diastolic component was heard over the precordium. The heart rate was $90 / \mathrm{min}$, blood pressure $115 / 80$ with no other change in the patient's condition. The insufflation was immediately stopped and the needle withdrawn. A few seconds tater the $\mathrm{FeTCO}_{2}$ increased from 3.8 to 4.2 per cent and then slowly decreased to 4.0 per cent over the next half minute (Figure 1). The patient's legs were taken out of the stirrups in preparation for left lateral decubitus positioning, but at this time the murmur softened and then disappeared. The patient was observed carefully for more than 10 min during which time there were no changes in the vital signs. The capnograph record then showed a gradual increase of the $\mathrm{FeTCO}_{2}$ to 4.5 per cent at which level it remained throughout the procedure. The needle was re-positioned and insufflation repeated uneventfully (Figure 2), and the laparoscopy was then completed with the postoperative diagnosis of extensive intraperitoneal adhesions. The patient awakened immediately after the procedure, at which time the ECG, chest $x$-ray and blood gases were normal. She subsequently had an uneventful course and was discharged the next day.

\section{Discussion}

Embolization of the insufflating gas during induction of pneumoperitoneum for laparoscopy is a sudden

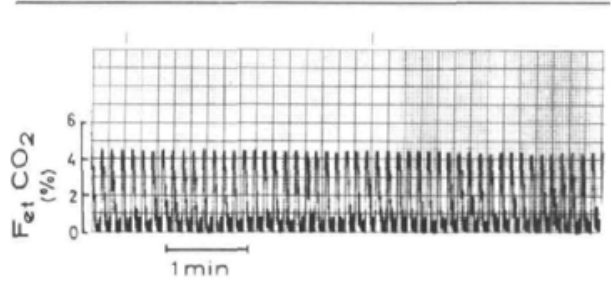

FIGURE 2 Fractional end tidal $\mathrm{CO}_{2}$ (per cent) ws time. Graph taken during the second insufflation and representative of the record throughout the procedure following the initial abortive insuffation.

dramatic event caused by accidental puncture of intraabdominal blood vessels with subsequent intravascular insufflation of the gas. The exact site of intravascular insertion of the needle is usually difficult to determine, ${ }^{9}$ though the uterine blood vessels are a likely site of entry of gas following intrauterine insertion of the needle. ${ }^{10}$ This approach to the peritonal cavity thus may predispose to gas embolism and is not recommended. Where intraperitoneal adhesions exist, they fix the otherwise mobile omentum to other structures and may similarly predispose to intravascular penetration and gas embolization. ${ }^{2}$

When gas is insufflated intravenously it is rapidly carried to the vena cava and right atrium where it forms a "gas lock." This is true both for air ${ }^{11,12}$ and for carbon dioxide, ${ }^{13}$ and can result in obstruction to venous return with a precipitous fall in cardiac output. The churning action of the heart breaks the gas up into small bubbles, producing a foam ${ }^{9}$ which can advance through the right heart and reach the pulmonary circulation, where it may cause pulmonary hypertension and right heart strain. ${ }^{9}$ The amount of gas which will advance in this way is less if the patient is in the left lateral decubitus position ${ }_{1}^{13,14}$ or in the steep head down position ${ }^{15}$ as the buoyant foam will then be displaced laterally and inferiorly respectively and out of the main blood channel. The size of the bubbles and the rate of the intravenous entry of the gas will also determine the likelihood of passage of the bubbles through the right heart. During neurosurgery the slow entrainment of small bubbles of air is more likely to result in air entrapment in the pulmonary vessels whereas during laparoscopy the rapid insufflation of gas under high pressure probably causes a "gas lock" in the vena cava and right atrium which would 
effectively trap subsequent bubbles and prevent gas entry into the pulmonary vessels. ${ }^{\prime \prime}$

Carbon dioxide is used most frequently for laparoscopy because it is more soluble in blood than either air or oxygen, and therefore a greater quantity of embolic carbon dioxide can be tolerated. ${ }^{16,17}$ Absorption of $\mathrm{CO}_{2}$ is rapid so that dissolution of the foam and reversal of the haemodynamic impairment quickly occur. The platelet aggregation and mediator-induced bronchospasm which occur at air/blood interfaces ${ }^{18}$ do not seem to occur with $\mathrm{CO}_{2}$ emboli. Thus reports of $\mathrm{CO}_{2}$ embolism have often commented on the rapid reversal of signs and the relatively benign postoperative course $9,10,15,19$

If however the disturbance is unrecognised and there is continued intravascular insufflation of the $\mathrm{CO}_{2}$, other gases, chiefly oxygen, begin to diffuse into the bubbles. ${ }^{20}$ The embolism then will require more time to be absorbed and a vicious cycle could be established. This may account for the reports of permanent injury ${ }^{6}$ and deaths ${ }^{5-7}$ following $\mathrm{CO}_{2}$ embolism, and emphasises the importance of prompt diagnosis by the anaesthetist in order to prevent a small embolus from enlarging.

The presenting signs of gas embolism during laparoscopy include sudden profound hypotension, cyanosis, tachycardia and other dysrhythmias, or an alteration in heart tones. The first sign may be pulmonary nedema, ${ }^{21}$ and delayed sudden death has also been reported. ${ }^{5}$

Before making the diagnosis of gas embolism, other causes of sudden cardiovascular collapse during laparoscopy must be eliminated, such as intra-abdominal haemorrhage, pulmonary thromboembolism, pneumothorax or pneumomediastinum, diaphragnatic rupture, excessive intra-abdominal pressure, vasovagal reflex, and hypoventilation which may cause dysrhythmias, especially in the presence of halothane.

Aspiration of gas or foamy blood from a central venous line will establish the diagnosis. Preoperative insertion of a central venous line routinely is not, however, always justified for a low risk procedure.

Diagnosis of gas embolism by non-invasive means and at an earlier stage would clearly be more beneficial, and monitoring of the heart sounds with a precordial or oesophageal stethoscope may accomplish this. Heart sound changes reliably detect air embolism $^{4}$ and may also help to establish the rate and quantity of air infused. ${ }^{11}$ Typical murmurs of air embolism may occur in the absence of clinical signs $^{4,22}$ and at times, even before changes in the heart sounds are heard on the Doppler apparatus. ${ }^{4,23}$ During $\mathrm{CO}_{2}$ insufflation for laparoscopy, the sudden onset of "mill wheel" murmurs in two cases, ${ }^{9,19}$ and of a coarse slosby murmur in another case ${ }^{15}$ was followed by cardiovascular collapse and was attributed to $\mathrm{CO}_{2}$ embolism. In our patient the sudden appearance of a murmur which had the characteristics of a "mill wheel" murmur, was highly suggestive of this diagnosis and immediate cessation of the insuffation probably prevented deterioration of the clinical status.

The most sensitive monitor of intra-cardiac gas is the oesophageal Doppler apparatus which can detect as little as $0.05 \mathrm{ml}$ of air. ${ }^{24}$ The precordial Doppler is sensitive to $2 \mathrm{ml}$ of $\mathrm{CO}_{2}$ injected into the right atrium, ${ }^{23}$ and has been used during laparoscopy in 100 patients, with no evidence of intra-cardiac gas. ${ }^{25}$ This would seem to confirm that gas embolism during laparoscopy does not commonly occur sub-clinically as is the case during ncurosurgery.

Other factors which should alert the observant anaesthetist are the presence of blood on aspiration from the Verres needle, pulsations of the flow meter with the patient's pulse during insufflation, ${ }^{15}$ and absence of signs of distention of the abdomen in spite of an adequate volume of insufflated gas.

Capnography is a useful non-invasive monitoring technique in anaesthesia which reflects reasonably accurately the arterial $\mathrm{CO}_{2}$ tension in patients without serious cardiopulmonary disease. ${ }^{26,27}$ The $\mathrm{FETCO}_{2}$ immediately reflects changes in ventilation and circulatory status as well as alterations in position and temperature of the patient. It is very sensitive to changes in lung mechanics which may occur during anaesthesia, especially changes in alveolar dead space. ${ }^{27.28}$

The patient described in this report showed a transient 0.4 per cent increase in $\mathrm{FETCO}_{2}$ which began a few seconds after the onset of the murmur. No comparable abrupt rise was noted in any one of 57 patients undergoing gynecologic laparoscopies monitored by capnography by one of us (DS). In these cases there was generally a very gradual rise of $\mathrm{FETCO}_{2}$ over the course of the laparoscopies (mean duration 32 min) which reached its maximum at the end of the procedure. The mean rise at this time was 0.2 per cent ( \pm 0.4 per cent) which is 
small compared to the mean rise found by Seed et al., ${ }^{26}$ probably because we tried to adjust the ventilation to maintain a constant $\mathrm{FETCO}_{2}$, in spite of the steep head down position of the patient. There were no changes in the heart sounds in any of these patients, all of whom were monitored with an oesophageal or pre-cordial stethoscope.

We know of no previous clinical case report of $\mathrm{CO}_{2}$ embolus where capnographic monitoring was coincidentally used. Oppenheimer et al. demonstrated in dogs that $\mathrm{CO}_{2}$ embolization caused a biphasic change in $\mathrm{PETCO}_{2}{ }^{29}$ The initial increase in $\mathrm{PETCO}_{2}$ was probably the result of excretion of $\mathrm{CO}_{2}$, which had been absurbed into the blood, by the lungs. The subsequent decrease was explained by blockage of the pulmonary arterioles by bubbles of $\mathrm{CO}_{2}$ resulting in increased alveolar dead space. This effect is similar to but less marked than that due to air emboli since $\mathrm{CO}_{2}$ emboli do not produce bronchoconstriction or changes in pulmonary compliance as do air bubbles ${ }^{18}$ and also disappear more rapidly from the pulmonary circulation. ${ }^{18}$ Thus a small $\mathrm{CO}_{2}$ embolus may produce only the initial rise in $\mathrm{FETCO}_{2}$ without a significant subsequent decrease.

In our patient there were no obvious causes for the simultaneous appearance of a heart murmur and a transient rise in $\mathrm{FETCO}_{2}$ other than $\mathrm{CO}_{2}$ embolus. The patient was in the horizontal position and there were no changes in the ventilator settings at that time. Absorption of $\mathrm{CO}_{2}$ from the peritoneum should not have been significant at the beginning of the procedure, ${ }^{26}$ nor were there subsequent disturbances in the otherwise smooth record of $\mathrm{FETCO}$ (Figure 2). Though not in itself sufficient to establish the diagnosis, the pattern seen on the capnograph record, coinciding with a transient heart murmur, is suggestive of $\mathrm{CO}_{2}$ embolus. Changes in $\mathrm{FeTCO}_{2}$ may in this way complement other signs of $\mathrm{CO}_{2}$ embolism and help to confirm this diagnosis.

Treatment of gas embolus consists initially of immediate cessation of the insufflation and placing the patient in the left lateral decubitus (Durant's) position. ${ }^{14}$ The steep head down position has also been advocated ${ }^{15}$ but since the gas bubble may be found at the junction of the inferior vena cava and the atrium, ${ }^{13}$ assumption of this position may cause the bubble to enter further into the cardiac chambers and this may increase the disturbance to blood flow. Discontinuing nitrous oxide will allow 100 per cent oxygen to be given, but will not result in reduction of the size of a $\mathrm{CO}_{2}$ embolus, as is the case with air embolus. This is due to the similarity of the solubilities in blood of $\mathrm{N}_{2} \mathrm{O}$ and $\mathrm{CO}_{2}{ }^{15}$ so that there will not be significant diffusion of $\mathrm{N}_{2} \mathrm{O}$ into or out of the $\mathrm{CO}_{2}$ bubbles. Hyperventilation will, however, increase $\mathrm{CO}_{2}$ excretion. If these simple measures are not rapidly effective, a central venous catheter may be introduced for aspiration of the gas, though Alvaran $e t a l .^{30}$ have shown in dogs that during air embolus aspiration of air in this way was no more effective than the left lateral decubitus position. Cardio-pulmonary resuscitation may be necessary in order to maintain oxygenation of vital organs.

In summary, we have described the sudden appearance during laparoscopy of a heart murmur that coincided with a transient rise in $\mathrm{FETCO}_{2}$ during insufflation of $\mathrm{CO}_{2}$ and we have attributed these findings to $\mathrm{CO}_{2}$ embolism. Early diagnosis and immediate cessation of the insufflation probably prevented progression of the haemodynamic disturbance. We recommend continuous monitoring of the heart sounds routinely during this procedure and, if available, capnographic monitoring which may provide information that will assist the anaesthetist in making the diagnosis of gas embolism early.

\section{References}

1 Phillips $J$, Keith $D$, Hulka J, Keith L. Gynecologic laparoscopy in 1975. J Reprod Med 1976; 16 : 205-17.

2 Bruhl W. Complications of laparoscopy and liver biopsy under vision: the results of a survey. German Med Monthly 1967; 12: 31-2.

3 Peterson HB, DeStefana F, Greenspan $J R$, Ory $H W$. Mortality associated with tubal sterilization in United States hospitals. Am J Obstet Gynecol 1982; 143 : 125-9.

4 Michenfelder JD, Martin JT, Alenburg BM, Rehder $K$. Air embolism during neurosurgery. JAMA 1969; 208: $1353-B$,

5 Rout B, Levy MN. Pollack S, Lubert M, Pathak K. Gas embolism death after laparoscopy delayed by trapping in the portal circulation. Anesth Analg 1978; 57: 232-7.

6 Ivankovich AD, Albrecht RF, Zahed B, Bonnet $R F$. Cardiovascular collapse during gynecological laparoscopy. Ill Med J 1974; 145: 58-61.

7 McKenzie R. Laparoscopy. NZ Med J 1971; 74: 87-91 
8 Blackburn JP, Williams TR. Evaluation of the Datex CD-101 and Godard capnograph mark II infra-red carbon dioxide analysers. Br J Anaesth 1980; 52: 551-5.

9 Yacoub OF, Cardona I, Coveler LA, Dodson MG. Carbon dioxide embolism during laparoscopy. Anesthesiology $1982 ; 57: 533-5$.

10 Morison DH, Riggs, JRA. Cardiovascular collapse in laparoscopy. Can Med Assoc J 1974; 111: 433-7.

11 Adornato DC, Gildenberg $P L$, Ferrario CM, Smart J, Frost EAM. Pathophysiology of intravenous air embolism in dogs. Anesthesiology 1978; 49: 120-7.

12 Benedetto AR, Hoff BH, Nusynowitz $M L$, Smith RB, Wilson $A$. Direct scintigraphic visualization of tight ventricular airlock in fatal venous air embolism in dogs (Abstract). Anesth Analg 1983; 62: 250.

13 Hipona FA, Ferres EJ, Pick R. Capnocavography, a new technique for examination of the inferior vena cava. Radiology 1969; 92: 606-9.

14 Durant TM, Oppenheimer MJ, Lynch PR, Ascanio G, Webber $D$. Body position in relation to venous air embolism: a roentgenological study. Am J Med Sci 1954; 227: 509-20.

15 Nichols SL, Tompkins BM, Henderson PA. Probable carbon dioxide embolism during laparascopy; case report. Wis Med J 1981; 80: 27-9.

16 Kunkler A, King H. Comparison of air, oxygen, and carbon dioxide embolization. Ann Surg 1959; 149: 95-9.

17 Graff TD, Arbegast NR, Phillips OC, Harris LC, Frazier TM, Baltimore SM. Gas embolism: a comparative study of air and carbon dioxide as embolic agents in the systemic venous system. Am J Obstet Gynecol 1959; 78: 259-65.

18 Khan MA, Alkalay I, Suetsugu S, Stein M. Acute changes in lung mechanics following pulmonary emboli of various gases in dogs. J Appl Physiol 1972; 33: 774-7.

19 Clark CC, Weeks DB, Gudson JP. Venous carbon dioxide embolism during laparoscopy. Anesth Analg 1977; 56: 650-2.

20 Stauffer HM, Durant TM, Oppenheimer MJ. Gas embolism. Radiology 1956; 66: 686-92.

21 Desai $S$, Roaf $E$, Liu $P$. Acute pulmonary edema during laparoscopy. Anesch Analg 1982; 61: 699-700.

$22 \mathrm{Ngai} S H$. Stinchfield FE, Trinder $L$. Air embolism during total hip arthroplasties. Anesthesiology 1974; 40: 405-7.

23. Micherfelder $J D$, Miller RH, Gronert GA. Evaluation of an ultrasonic device (Doppler) for the diagnosis of venous air embolism. Anesthesiology 1972; 36: 164-7.

24 Martin RJ, Colley PS. Evaluation of transoesophageal Doppler detection of air embolism in dogs. Ancsthesiology 1983; 58: 117-23.

25 Wadhwa RK, MCKenzie R, Wadhwa SR, Katz $D L$, Byers.JF. Gas embolism during laparoscopy. Anesthesiology 1978; 48: 74-6.

26 Seed RF, Shakespeare TF, Muldoon MJ. Carbon dioxide homeostasis during anesthesia for laparoscopy. Anaesthesia 1970; 25: 223-31.

27 Smalhout B. Kalenda $Z$. An atlas of capnography, vol 1. The Netherlands: Kerchkebosch-Zeist 1975.

28 Nunn JF. Applied respiratory physiology, second edition. London: Butterworths 1977.

29 Oppenheimer MJ, Durant TM, Stauffer HM, Steward $G H$, Lynch $P R$, Barrera $F$. In vivo visualization of intracardiac structures with gaseous carbon dioxide. Am J Physial 1956; 186: 325-34.

30 Alvaran SB, Toung JK, Graff TE, Benson DW. Venous air embolism: comparative merits of external cardiac massage, intracardiac aspiration, and left lateral decubitus position. Anesth Analg 1978; 57 : $66-70$.

Résumé

Une embolie de gaz carbonique a été détectée pendant une laparoscopie diagnostique chez une femme en bonne santé. Le diagnostic a été posé grâce à l'apparition subite de souffies cardiaques systolique et diastolique caractéristiques. L'enregistrement continu de la pression partielle. de $\mathrm{CO}_{2}$ télé-expiratoire $\left(\mathrm{F}_{\mathrm{ET}} \mathrm{CO}_{2}\right)$ a montré une élévation abrupte de 3.8 à 4.2 pour cent puis une descente lente à 4.0 pour cent en 30 secondes. L'insufflation de $\mathrm{CO}_{2}$ fut arrêtée dès le diagnostic posé. La patiente a récuperé sans problème. Une élévation rapide et transitoire de $\mathrm{FETCO}_{2}$ semble ètre un signe précoce utile de l'embolie de $\mathrm{CO}_{2}$ pendant une laparoscopie. 